\section{Low-temperature Storage of Micropropagated Plantlets under Selected Light Environments}

\author{
Chieri Kubota ${ }^{1}$ and Nihal C. Rajapakse \\ Department of Horticulture, Clemson University, Clemson, SC 29634-0375
}

\author{
Roy E. Young \\ Department of Agricultural and Biological Engineering, Clemson University, \\ Clemson, SC 29634-0357
}

Additional index words. $\mathrm{CO}_{2}$ concentration, growth measurements, environment control, growth suppression, light quality, light intensity

\begin{abstract}
Broccoli (Brassica oleracea L. Botrytis Group 'Green Duke') and Hosta tokudama F. Maekawa 'Newberry Gold' plantlets, which were ready for transplanting after photoautotrophic (sugar-free) culture, were stored 4 to 6 weeks at $5 \mathrm{C}$ under various light qualities and photosynthetic photon fluxes (PPF). Illumination during storage maintained quality, photosynthetic ability, and regrowth potential of plantlets stored at low temperature. PPF affected quality of broccoli and Hosta plantlets. Broccoli plantlets responded to storage light quality, while Hosta did not. White light maintained the quality of broccoli plantlets better during 6 weeks of storage than did red or blue light. Red and blue light caused an increase in internode length and reduction in chlorophyll concentrations compared to white light. Photosynthetic and regrowth potentials of plantlets were not affected by spectral quality during storage. Considering changes in dry weight, stem length, and leaf yellowing, the quality of broccoli plantlets was best maintained under white light at $2 \mu \mathrm{mol} \cdot \mathrm{m}^{-2} \cdot \mathrm{s}^{-1}$ PPF. PPF and light quality were shown to be important factors in the preservation of transplant quality and suppression of growth of the plantlets during low-temperature storage.
\end{abstract}

In vitro plantlets are sometimes ready for transplanting before labor or greenhouse space for acclimatization is available or before seasonal and global markets are ready. A crucial question exists of how to store quality micropropagated transplants in a "no-growth" status to meet flexible, market demands while limiting production and labor costs.

Low-temperature storage has been used widely to maintain quality of harvested horticultural products, yet there is minimal information on maintenance of quality in micropropagated plantlets before shipping or transplanting. Low-temperature storage of in vitro plantlets has been investigated primarily as an alternative to frequent subculturing for maintenance and genetic conservation of stock materials (Grout, 1995). For this type of storage, viability and genetic stability are the most important considerations for selecting desirable storage environments. Overall quality (vigor and morphology) and photosynthetic

Received for publication 31 July 1995. Accepted for publication 11 Jan. 1996. We are grateful for financial support from the Clemson Univ. Ornamentals Enhancement Program. Technical Contribution no. 4107 of the South Carolina Agricultural Experiment Station. The cost of publishing this paper was defrayed in part by the payment of page charges. Under postal regulations, this paper therefore must be hereby marked advertisement solely to indicate this fact.

${ }^{1}$ To whom reprint requests should be addressed Current address: Dept. of Bioproduction Science, Chiba Univ., Matsudo Chiba 271, Japan. ability also should be preserved for storage of transplants.

Storage conditions for in vitro genetic conservation of temperate genera are typically 4 or 5C in darkness (Reed, 1993). However, positive effects of illumination during storage were reported. Dorion et al. (1991) successfully stored 'Mme Delbard' and 'Eterna' roses at 2 to $4 \mathrm{C}$ under 9 to $18 \mu \mathrm{mol} \cdot \mathrm{m}^{-2} \cdot \mathrm{s}^{-1}$ photosynthetic photon flux (PPF) (8-h photoperiod) for 6 months. Baubault et al. (1991) reported that in vitro Rhododendron 'Purple Splendour' was successfully stored at $4 \mathrm{C}$ under 30 $\mu \mathrm{mol} \cdot \mathrm{m}^{-2} \cdot \mathrm{s}^{-1} \mathrm{PPF}$ (14-h photoperiod) for 6 or 12 months. For maintaining high-quality micropropagated plantlets in stage 3 (in vitro rooting stage before acclimatization), broccoli plantlets required illumination as low as the light compensation point $\left(2 \mu \mathrm{mol} \cdot \mathrm{m}^{-2} \cdot \mathrm{s}^{-1} \mathrm{PPF}\right.$, 24-h photoperiod) at 5C (Kubota and Kozai, 1994, 1995; Kubota et al., 1995).

Cool-white fluorescent lamps were used during most published studies on storage. Light quality has been observed to influence plant growth and morphology of plants ex vitro (Smith, 1982) and in vitro (Economou and Read, 1987) at ambient temperatures. Quality of light in low-temperature storage also may influence growth, morphology, and other quality characteristics of transplants, but to our knowledge, little work has been reported in this area. In this study, we investigated the effects of light quality and PPF on morphology, photosynthesis, and regrowth potential of in vitro plantlets in low-temperature storage.
Plant materials and treatments

Influence of blue and white light at two levels of PPF on storage of broccoli and Hosta plantlets (Expt. 1). 'Green Duke' broccoli plantlets (germinated from surface-disinfested seeds) and stage 3 Hosta tokudama 'Newberry Gold' plantlets were cultured in vitro for 3 and 4 weeks, respectively, under photoautotrophic (no sugar in the medium) conditions. Four plantlets were cultured in each Magenta vessel $(375 \mathrm{ml})$ with $50 \mathrm{ml}$ Murashige and Skoog (1962) gelled (agar at $8 \mathrm{~g} \cdot$ liter $^{-1}$ ) medium. The vessels were estimated to have 3.6 air exchanges per hour according to the method described by Kozai et al. (1986). Culture room temperature was $23 \pm 2 \mathrm{C} / 19 \pm 1 \mathrm{C}$ during the photo-/dark periods (16-h photoperiod). The PPF was $140 \pm 20 \mu \mathrm{mol} \cdot \mathrm{m}^{-2} \cdot \mathrm{s}^{-1}$ on the culture shelf. At the end of culture, vessels were stored for 4 weeks at $5 \mathrm{C}$ under $15-\mathrm{W}$ cool-white fluorescent lamps (General Electric F15T12CW) wrapped with Roscolux no. 74 blue acetate film (Rosco, Port Chester, N.Y.) (blue light) or a $15-\mathrm{W}$ cool-white fluorescent lamp (white light) that provided a $24-\mathrm{h}$ photoperiod. Spectral distributions inside an empty vessel under blue light were shifted toward the shorter wavelengths relative to white light (Fig. 1). Under each light source, PPF inside vessels during storage was adjusted to either $1 \pm 0.5$ or $3 \pm 0.5 \mu \mathrm{mol} \cdot \mathrm{m}^{-2} \cdot \mathrm{s}^{-1}$. During storage, the number of air exchanges of the vessel was $0.1 / \mathrm{h}$ to avoid excessive water loss.

Influence of blue, red, and white light on storage of broccoli plantlets (Expt. 2). Stage 3 'Green Duke' broccoli plantlets were cultured photoautotrophically for 2 weeks under $\mathrm{CO}_{2}$ concentration of $1100 \mu \mathrm{mol} \cdot \mathrm{mol}^{-1}$. Cellulose supports (Sorbarod, Baumgartner Papiers, Switzerland) were used with liquid MS medium ( $8 \mathrm{ml} /$ plantlet). Culture vessels and the other culture conditions were the same as in Expt. 1. At the end of culture, vessels were stored for 3 or 6 weeks in darkness or under a 20-W blue fluorescent lamp (General Electric F20T12-B) (blue light), 15-W cool-white fluorescent lamps wrapped with Roscolux no. 26 red film (red light), or 15-W cool-white fluorescent lamps (white light) that provided a 24 $\mathrm{h}$ photoperiod. PPF during storage was 0 (darkness) or $2 \pm 0.5 \mu \mathrm{mol} \cdot \mathrm{m}^{-2} \cdot \mathrm{s}^{-1}$ (inside empty vessels). Spectral distributions of the three light sources measured inside the empty vessels differed substantially in the location of peaks (Fig. 2).

After 3 or 6 weeks of storage, plantlets were acclimatized for 5 days in a growth chamber with frequent hand-misting under $140 \mu \mathrm{mol} \cdot \mathrm{m}^{-2} \cdot \mathrm{s}^{-1} \mathrm{PPF}$. After acclimatization, plantlets were transplanted into a glass greenhouse set at 27C. The 3-week stored and the 6week stored plantlets were grown in the greenhouse from 3 Oct. through 5 Dec. (average photoperiod 12 to $11 \mathrm{~h}$ ), and from 24 Oct. through 26 Dec. 1994 (average photoperiod 11 to $10 \mathrm{~h}$ ), respectively. As a nonstored control, plantlets were cultured for 2 weeks and then acclimatized and transplanted at the same 


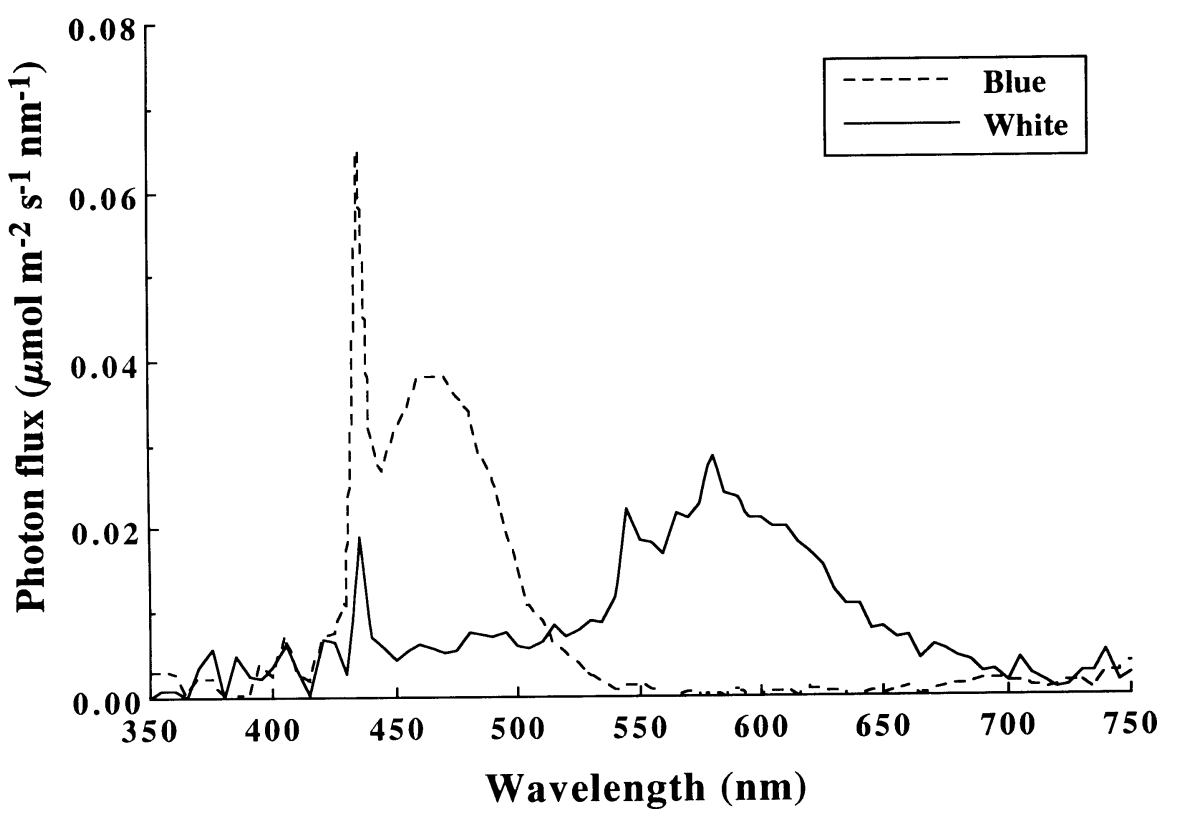

Fig. 1. Spectral photon flux distributions of storage light sources measured inside a vessel (Expt. 1).

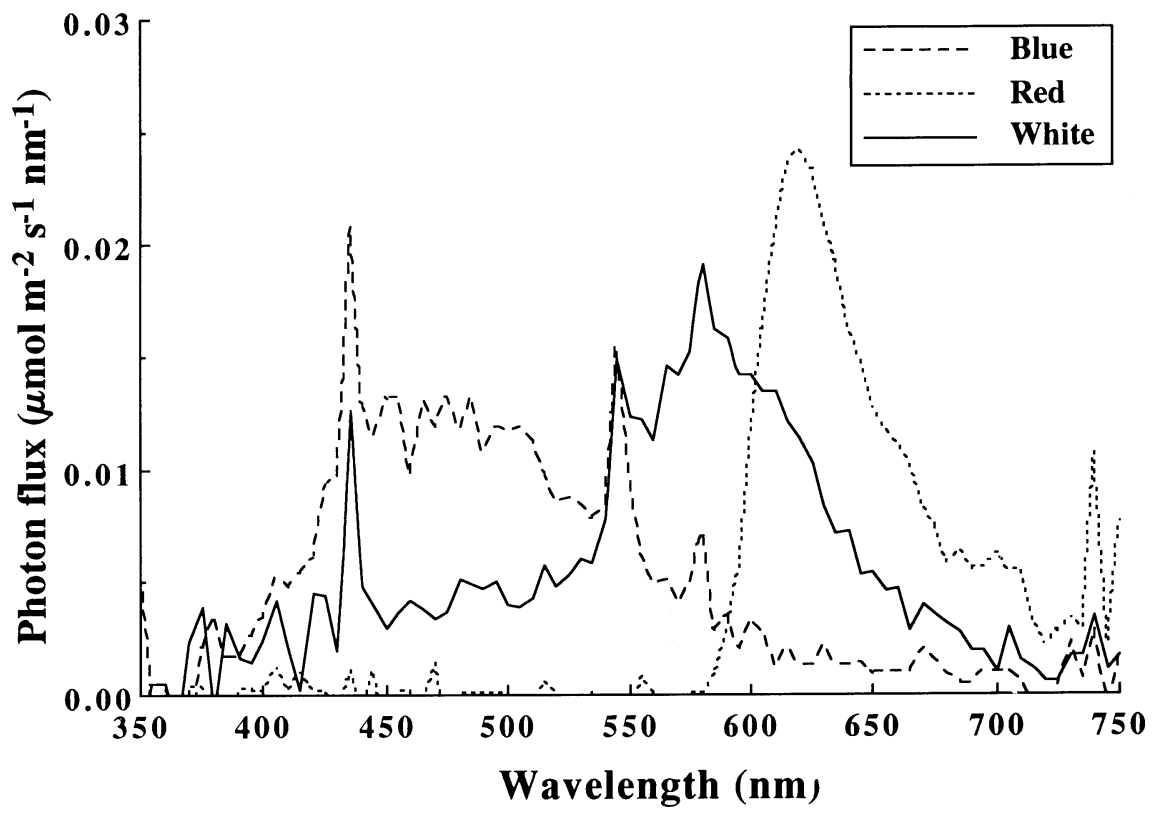

Fig. 2. Spectral photon flux distributions of storage light sources measured inside a vessel (Expt. 2).

time as the plantlets stored for 3 or 6 weeks. Plants were grown in plastic pots containing a commercial potting mix (mix 3B; Fafard, Anderson, S.C.) and irrigated once daily with a nutrient solution containing $\mathrm{N}, \mathrm{P}$, and $\mathrm{K}$ at 200, 90, and $170 \mathrm{mg} \cdot \mathrm{liter}^{-1}$, respectively, from Peter's 20-20-20 fertilizer (W.R. Grace Co., Fogelsville, Pa.).

\section{Measurements}

Shoot and root dry weights, plantlet height (total length of hypocotyl and epicotyl for broccoli and shoot height for Hosta), and number of leaves were measured on harvested plantlets before and after 4 weeks of storage in Expt. 1. In Expt. 2, only shoot dry weight was measured because of the difficulty of separation of roots from the fibrous supports. Stem
NPR were calculated from $\mathrm{CO}_{2}$ concentrations inside and outside of the vessel and number of air exchanges in the vessel, as described by Fujiwara et al. (1987). A model, $\mathrm{NPR}=\mathrm{k}_{1}\left[1-\exp \left\{-\mathrm{k}_{2}\left(\mathrm{CO}_{2}-\mathrm{k}_{3}\right) / \mathrm{k}_{1}\right\}\right]$, was fitted for each treatment (except for darkness). The variable $\mathrm{CO}_{2}$ represents $\mathrm{CO}_{2}$ concentration inside the vessel. Parameters $\mathrm{k}_{1}, \mathrm{k}_{2}$, and $\mathrm{k}_{3}$ represent maximum photosynthetic rate, initial slope, and $\mathrm{CO}_{2}$ compensation point, respectively, and they were estimated and compared statistically using the SAS NLIN program.

Stem length and number of leaves were recorded weekly for 9 weeks after transplanting into a greenhouse. Days to set visible flower buds were recorded, and final shoot dry weight was measured 9 weeks after transplanting.

Number of vessels per treatment was four and 14, which gave 16 and 56 plantlets per treatment in Expts. 1 and 2, respectively. Two vessels were harvested from each treatment before and after storage in Expt. 1 and five vessels per treatment in Expt. 2. Plantlets from two vessels from each treatment were transplanted and harvested in the greenhouse. Each vessel with four plantlets was considered as a replication. The experiments were conducted once. Statistical differences between plantlets before and after storage and between stored and nonstored plantlets were determined by $t$ test. The statistical significances among storage treatments were determined by analysis of variance.

\section{Results}

Experiment 1. Dry weight of the broccoli plantlets after storage was similar to that before storage for all treatments. Light quality significantly affected plantlet height and leaf yellowing of the broccoli plantlets. The plantlets elongated during 4 weeks of storage under blue light and more at the high than the low PPF (Table 1). Elongation was nonsignificant for the broccoli plantlets under white light at either PPF. The percentage of yellow leaf area increased in broccoli plantlets stored under blue light. Leaf yellowing was absent under white light.

Hosta plantlets significantly responded to PPF in storage but not to light quality (Table 1). Neither dry weight nor plantlet height was affected by the storage treatments. More leaves deteriorated (i.e., no longer were green) at the low PPF than at the high PPF in white and blue lights.

Experiment 2. The shoot dry weight of the broccoli plantlets was reduced significantly in darkness during 6 weeks of storage. Regardless of spectral quality, light was necessary in storage to maintain plantlet dry weight at 3 weeks at a level similar to that measured before storage (Table 2). The dry weight and number of leaves remained unchanged throughout the 6 weeks of storage under red and white light, but there was a significant $(P \leq 0.05)$ increase in dry weight and number of leaves in plantlets stored under blue light for 6 weeks.

Stem elongation was significant during 3 and 6 weeks of storage under blue and red 
Table 1. Light quality and quantity effects on broccoli and Hosta plantlet characteristics before and after 4 weeks of storage at $5 \mathrm{C}$ (Expt. 1). Means $\pm \mathrm{SE}$ are shown.

\begin{tabular}{|c|c|c|c|c|c|c|c|}
\hline \multicolumn{2}{|c|}{ Light treatments } & \multicolumn{3}{|c|}{ Broccoli } & \multicolumn{3}{|c|}{ Hosta } \\
\hline Quality & $\begin{array}{c}\mathrm{PPF}^{\mathrm{z}} \\
\left(\mu \mathrm{mol} \cdot \mathrm{m}^{-2} \cdot \mathrm{s}^{-1}\right)\end{array}$ & $\begin{array}{l}\text { Dry wt } \\
(\mathrm{mg})\end{array}$ & $\begin{array}{c}\mathrm{Ht} \\
(\mathrm{mm})\end{array}$ & $\begin{array}{c}\text { Yellow } \\
\text { area }(\%)\end{array}$ & $\begin{array}{l}\text { Dry wt } \\
(\mathrm{mg})\end{array}$ & $\begin{array}{c}\mathrm{Ht} \\
(\mathrm{mm})\end{array}$ & $\begin{array}{c}\text { Green leaves } \\
\text { (no.) }\end{array}$ \\
\hline \multicolumn{8}{|c|}{ Before storage } \\
\hline & & $31 \pm 2.3$ & $38 \pm 2.3$ & $0 \pm 0$ & $52 \pm 1.5$ & $24 \pm 3.7$ & $8 \pm 1.4$ \\
\hline \multicolumn{8}{|c|}{ After 4 weeks of storage } \\
\hline Blue & $1 \pm 0.5$ & $36 \pm 1.7^{\mathrm{Ns}}$ & $54 \pm 1.6^{*}$ & $20 \pm 0.2^{* *}$ & $48 \pm 2.8^{\mathrm{Ns}}$ & $21 \pm 5.5^{\mathrm{vs}}$ & $1 \pm 0.1^{*}$ \\
\hline & $3 \pm 0.5$ & $37 \pm 1.1^{\mathrm{Ns}}$ & $65 \pm 1.4^{* *}$ & $12 \pm 6.1^{*}$ & $52 \pm 5.1^{\mathrm{Ns}}$ & $26 \pm 0.8^{\mathrm{Ns}}$ & $4 \pm 1.5^{\mathrm{Ns}}$ \\
\hline White & $1 \pm 0.5$ & $37 \pm 1.2^{\mathrm{Ns}}$ & $46 \pm 2.3^{\mathrm{Ns}}$ & $0 \pm 0^{\mathrm{Ns}}$ & $50 \pm 0.6^{\mathrm{NS}}$ & $25 \pm 1.7^{\mathrm{Ns}}$ & $0 \pm 0.1^{*}$ \\
\hline & $3 \pm 0.5$ & $41 \pm 0.6^{\mathrm{Ns}}$ & $46 \pm 0.4^{\mathrm{Ns}}$ & $0 \pm 0^{\mathrm{Ns}}$ & $53 \pm 2.9^{\mathrm{Ns}}$ & $24 \pm 0.3^{\mathrm{Ns}}$ & $4 \pm 0.6^{\mathrm{NS}}$ \\
\hline \multicolumn{8}{|l|}{ ANOVA $^{y}$} \\
\hline Quality & & NS & ** & ** & NS & NS & NS \\
\hline PPF & & NS & * & NS & NS & NS & * \\
\hline $\mathrm{Q} \times \mathrm{P}$ & & NS & * & NS & NS & NS & NS \\
\hline
\end{tabular}

${ }^{2} \mathrm{PPF}=$ photosynthetic photon flux

${ }^{y}$ Significance among the treatments; ANOVA = analysis of variance.

Ns, *** Nonsignificantly or significantly different from those before storage at $P \leq 0.05$ or 0.01 , respectively.

Table 2. Light quality effects on broccoli plantlet characteristics before and after 3 or 6 weeks of storage at $5 \mathrm{C}, 2 \mu \mathrm{mol} \cdot \mathrm{m}^{-2} \cdot \mathrm{s}^{-1}$ photosynthetic photon flux (Expt. 2). Means \pm SE are shown.

\begin{tabular}{|c|c|c|c|c|c|}
\hline \multirow[b]{2}{*}{ Light } & \multirow[b]{2}{*}{$\begin{array}{l}\text { Dry wt } \\
\text { (mg) }\end{array}$} & \multirow[b]{2}{*}{ No. leaves } & \multirow[b]{2}{*}{$\begin{array}{l}\text { Stem length } \\
(\mathrm{mm})\end{array}$} & \multicolumn{2}{|c|}{ Chlorophyll } \\
\hline & & & & $\begin{array}{c}\text { Concn } \\
\left(\mathrm{mg} \cdot \mathrm{m}^{-2}\right)\end{array}$ & $\begin{array}{l}\mathrm{a}: \mathrm{b} \\
\text { ratio }\end{array}$ \\
\hline \multicolumn{6}{|c|}{ Before storage } \\
\hline --- & $58 \pm 1.1$ & $4.0 \pm 0.09$ & $33 \pm 1.1$ & $516 \pm 13$ & $2.8 \pm 0.02$ \\
\hline \multicolumn{6}{|c|}{ After 3 weeks of storage } \\
\hline Blue & $61 \pm 1.0^{\mathrm{Ns}}$ & $4.2 \pm 0.10^{\mathrm{vs}}$ & $42 \pm 2.0^{*}$ & $315 \pm 7^{* *}$ & $2.6 \pm 0.02^{* *}$ \\
\hline Red & $64 \pm 2.0^{\mathrm{Ns}}$ & $4.3 \pm 0.08^{\mathrm{Ns}}$ & $40 \pm 1.3^{*}$ & $262 \pm 13^{* *}$ & $2.5 \pm 0.04^{* *}$ \\
\hline White & $60 \pm 1.1^{\mathrm{Ns}}$ & $4.2 \pm 0.14^{\mathrm{Ns}}$ & $35 \pm 1.3^{\mathrm{Ns}}$ & $379 \pm 16^{* *}$ & $2.6 \pm 0.03^{* *}$ \\
\hline ANOVA $^{z}$ & NS & NS & NS & $* *$ & $*$ \\
\hline \multicolumn{6}{|c|}{ After 6 weeks of storage } \\
\hline Darkness $^{y}$ & $42 \pm 3.4^{* *}$ & $4.2 \pm 0.05^{\mathrm{Ns}}$ & $31 \pm 1.6^{\mathrm{Ns}}$ & $320 \pm 14^{* * *}$ & $2.0 \pm 0.04^{* *}$ \\
\hline Blue & $64 \pm 1.6^{*}$ & $4.7 \pm 0.06^{*}$ & $46 \pm 2.3^{* *}$ & $154 \pm 31^{* *}$ & $2.3 \pm 0.03^{* *}$ \\
\hline Red & $62 \pm 1.8^{\mathrm{Ns}}$ & $4.3 \pm 0.07^{\mathrm{Ns}}$ & $45 \pm 1.4^{* *}$ & $254 \pm 38^{* *}$ & $2.3 \pm 0.02^{* *}$ \\
\hline White & $60 \pm 1.1^{\mathrm{Ns}}$ & $4.5 \pm 0.10^{\text {ss }}$ & $38 \pm 2.2^{\mathrm{Ns}}$ & $322 \pm 40^{* * *}$ & $2.6 \pm 0.02^{* *}$ \\
\hline ANOVA $^{z}$ & NS & NS & $*$ & $*$ & $* *$ \\
\hline
\end{tabular}

${ }^{2}$ Significance among the blue, red, and white light treatments; ANOVA = analysis of variance.

${ }^{y}$ Measured after 6 weeks only.

${ }_{\text {ss, }, * * *}$ Nonsignificantly or significantly different from those before storage at $P \leq 0.05$ or 0.01 , respectively.

light. Stem length increased as duration of storage increased. In white light or in darkness, stem length after 6 weeks of storage was at about the same as before storage.

Chlorophyll concentrations of the leaves had significantly decreased by 3 and 6 weeks of storage in all the treatments (Table 2). Chlorophyll concentrations were relatively high in plantlets stored under white light or in darkness compared to those under blue or red light at 3 or 6 weeks of storage. The chlorophyll $a: b$ ratio decreased regardless of treatment and was maintained at the highest level in white light during 6 weeks of storage.

Regardless of spectral quality, illumination in storage maintained $\mathrm{CO}_{2}$ concentrations inside the vessel 100 to $150 \mu \mathrm{mol} \cdot \mathrm{mol}^{-1}$ lower than outside the vessel (400 to 450 $\mu \mathrm{mol} \cdot \mathrm{mol}^{-1}$ ) throughout the 6 weeks of storage (data not shown). In darkness, $\mathrm{CO}_{2}$ accumulated and the $\mathrm{CO}_{2}$ concentration in the culture vessel was $\approx 2000 \mu \mathrm{mol} \cdot \mathrm{mol}^{-1}$ after 1 week of storage. These observations indicated that plantlets stored under illumination kept positive photosynthetic rates, while plantlets in darkness respired $\mathrm{CO}_{2}$. No significant amount of ethylene accumulated in the vessels regardless of treatment throughout the 6 weeks of storage (data not shown).
Photosynthetic response as a function of $\mathrm{CO}_{2}$ concentration before initiation of acclimatization showed that photosynthetic capability of plantlets stored under light was similar to those of nonstored plantlets (Fig. 3). Dark-stored plantlets had deteriorated and did not show positive photosynthetic rates at $\mathrm{CO}_{2}$ $<1000 \mu \mathrm{mol} \cdot \mathrm{mol}^{-1}$. The dark-stored plantlets died during the first 1 to 2 days of acclimatization. Model parameters $\mathrm{k}_{1}$ (maximum photosynthetic rate), $\mathrm{k}_{2}$ (initial slope), and $\mathrm{k}_{3}\left(\mathrm{CO}_{2}\right.$ compensation point) were, respectively, 10.4 $\pm 0.20,0.06 \pm 0.004$, and $49.1 \pm 6.62$ for control; $10.4 \pm 0.18,0.04 \pm 0.003$, and $41.4 \pm$ 7.99 for blue; $9.3 \pm 0.30,0.04 \pm 0.006$, and $56.7 \pm 11.43$ for red; $8.7 \pm 0.36,0.04 \pm 0.008$, and $46.8 \pm 17.50$ for white light treatment. The maximum photosynthetic rates were higher for nonstored plantlets and for plantlets stored in blue light than for plantlets stored in red or white light. The initial slopes were lower for stored plantlets under light than those for nonstored control plantlets. The $\mathrm{CO}_{2}$ compensation points were not significantly different between nonstored plantlets and plantlets stored in either blue, red, or white lights.

Regardless of storage light quality, all the plantlets stored for 3 weeks in light grew satisfactorily in the greenhouse and had dry weights, number of leaves, and stem lengths similar to nonstored plants (control A) after 9 weeks in the greenhouse (Table 3). Shoot dry weights of the plants stored for 6 weeks in blue or red light were not significantly different from those of nonstored plants (control B), while those of the plants stored for 6 weeks in white light had significantly lower shoot dry weight than those of nonstored plants. Plants stored in red or white light had a similar number of leaves as the nonstored plants, while significantly more leaves were produced by the plants stored in blue light. Regardless of light quality, after 9 weeks in the greenhouse, stem lengths of the plants that had been stored in light were not significantly different from those for nonstored control plants. Days to set flower buds of plantlets stored for 3 or 6 weeks were not significantly different from those of nonstored plants (data not shown). However, variations were wider for plants stored for 6 weeks (range from 53 to 63 days) than for plants stored for 3 weeks (range from 58 to 59 days).

\section{Discussion}

Influence of PPF. Both broccoli and Hosta plantlets responded to the small difference of PPF $\left(2 \mu \mathrm{mol} \cdot \mathrm{m}^{-2} \cdot \mathrm{s}^{-1}\right)$ in storage. Our preliminary experiment indicated that the light compensation point of broccoli and Hosta was around 2 and $3 \mu \mathrm{mol} \cdot \mathrm{m}^{-2} \cdot \mathrm{s}^{-1} \mathrm{PPF}$, respectively, at 5C. Kubota and Kozai (1994) reported that plantlets' dry weight and quality were best maintained when stored at low temperature under continuous illumination at close to their light compensation point. Higher PPF than the light compensation point stimulated undesirable shoot elongation during storage. Differences of 2 and $5 \mu \mathrm{mol} \cdot \mathrm{m}^{-2} \cdot \mathrm{s}^{-1} \mathrm{PPF}$ caused significant differences in dry weight and shoot length during 6 weeks of storage (Kubota et al., 1995). At 4 weeks of storage in Expt. 1, dry weights were similar for 1 and $3 \mu \mathrm{mol} \cdot \mathrm{m}^{-2} \cdot \mathrm{s}^{-1}$ PPF either in blue or white light; however, differences might occur during longer storage.

In darkness, broccoli plantlets could not be stored successfully for 6 weeks. Plantlets in darkness lost dry weight; their net photosynthetic response curves showed that they lost photosynthetic ability during storage, although their chlorophyll concentrations were maintained at similar or higher levels than those stored in light. Kubota and Kozai (1994) showed that plantlets that had been stored in darkness had lower chlorophyll fluorescence and, therefore, lower photosynthetic activity than plantlets that had been stored in light.

Influence of light quality. Light quality during storage affected the quality of broccoli plantlets stored at low temperature, but did not affect Hosta plantlets. Thus, the light quality effect was species-dependent.

Blue light enhanced shoot elongation of broccoli plantlets in both experiments. Shoot elongation is, however, often reported to be suppressed in blue light at $>30 \mu \mathrm{mol} \cdot \mathrm{m}^{-2} \cdot \mathrm{s}^{-1}$ PPF (Appelgren, 1990; Maijer, 1968; Mortensen and Stromme, 1987); blue light effects on stem elongation may be different at 


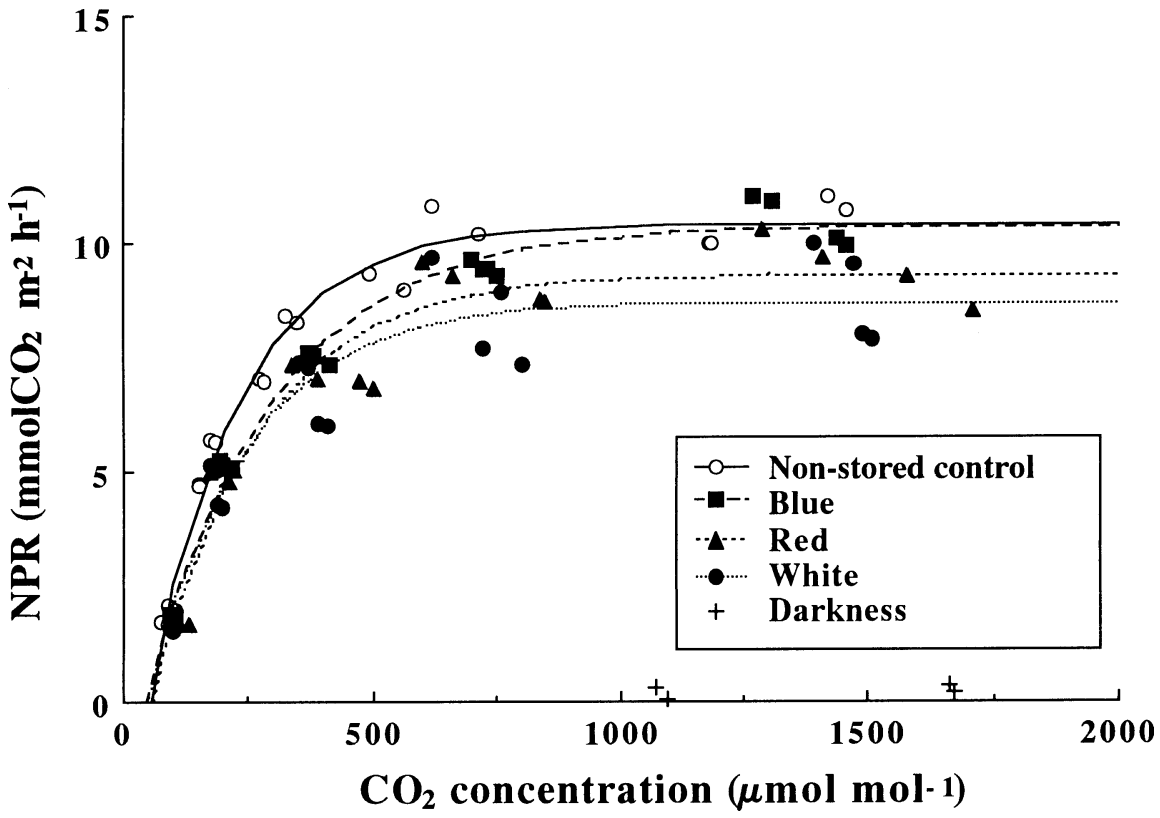

Fig. 3. Net photosynthetic rate (NPR) per unit leaf area of nonstored control plantlets and plantlets stored 6 weeks under various light conditions. NPR was measured under white light of $140 \mu \mathrm{mol} \cdot \mathrm{m}^{-2} \cdot \mathrm{s}^{-1}$ photosynthetic photon flux at $23 \pm 2 \mathrm{C}$ before acclimatization. Data were fitted with the model NPR $=$ $\mathrm{k}_{1}\left[1-\exp \left\{-\mathrm{k}_{2}\left(\mathrm{CO}_{2}-\mathrm{k}_{3}\right) / \mathrm{k}_{1}\right\}\right]$. Parameters for each treatment were shown in the text. The $r^{2}$ values are $0.96,0.99,0.98$, and 0.95 for nonstored control, blue, red, or white light, respectively.

lower light levels. In Expt. 2, shoot elongation was significant under blue and red lights at a PPF of $2 \mu \mathrm{mol} \cdot \mathrm{m}^{-2} \cdot \mathrm{s}^{-1}$. Stem elongation was enhanced when Pelargonium plantlets were grown in red light at $30 \mu \mathrm{mol} \cdot \mathrm{m}^{-2} \cdot \mathrm{s}^{-1} \mathrm{PPF}$ (Appelgren, 1990).

Chlorophyll concentration and chlorophyll $\mathrm{a}: \mathrm{b}$ ratio of stored broccoli leaves were affected by storage light quality. In Expt. 2, chlorophyll degradation was more pronounced in blue and red light than in white light or in darkness during 6 weeks of storage. The chlorophyll concentrations were lower in plantlets maintained under blue than under red light during 6 weeks of storage. Accumulation of pigments and pigment proteins were reportedly less in plants maintained under blue than under red light of equal photon flux (Eskins et al., 1989). Reduction in chlorophyll a : b ratio of the plantlets stored in red light for 3 weeks and in blue light for 6 weeks may indicate that synthesis of chlorophyll a and b was affected by light quality.

Light quality during storage did not significantly affect the photosynthetic ability and regrowth potential of the stored broccoli plantlets. However, shoot elongation during storage may cause difficulties in handling or undesirable lodging of the plantlets during acclimatization. Yellow leaves may reduce the value of plantlets when they are to be sold to customers immediately after storage. Days to set flower buds of the plants stored for 3 or 6 weeks were not significantly different from those of the nonstored control plants. However, the wider variation observed in the plants stored for 6 weeks may cause a problem for controlling flowering, especially for $\mathrm{F}_{1}$ hybrid seed production, where micropropagated plantlets are sometimes used as parent lines.

Illumination in low-temperature storage maintained quality, photosynthetic ability, and regrowth potential of plantlets. The PPF in storage affected quality of broccoli and Hosta plantlets. Light quality affected the transplant quality of broccoli. White light maintained better quality of broccoli plantlets after 6 weeks of storage than blue or red light, although photosynthetic and regrowth potentials of plantlets were not affected by light quality. Storage light sources should be carefully selected to provide uniform light distribution in terms of its quality and quantity for better maintenance of dry weight, transplant quality, and photosynthetic and regrowth potentials of the plantlets.

\section{Literature Cited}

Appelgren, M. 1990. Effects of light quality on stem elongation of Pelargonium in vitro. Scientia Hort. 45:345-351.

Baubault, C., V. Lanoy, F. Baudier, and C. Ducommun. 1991. In vitro preservation of Rhododendron during multiplication stage. Acta Hort. 298:355-358.

Dorion, N., M. Kadri, and C. Bigot. 1991. In vitro preservation at low temperatures of rose plantlets. Acta Hort. 298:335-347.

Economou, A.S. and P.E. Read. 1987. Light treatments to improve efficiency of in vitro propagation systems. HortScience 22:751-754.

Eskins, K., P. Westhoff, and P.D. Beremand. 1989. Light quality and irradiance level interaction in the control of expression of light-harvesting complex of photosystem II. Plant Physiol. 91:163-169.

Fujiwara, K., T. Kozai, and I. Watanabe. 1987. Fundamental studies on environments in plant tissue culture vessels. (3) Measurements of carbon dioxide gas concentration in closed vessels containing tissue cultured plantlets and estimates of net photosynthetic rates. J. Agr.

Grout, B.W.W. 1995. Low temperature storage of Meteorol. 43(1):21-30.
Table 3. Light quality effects on broccoli plantlet characteristics after 9 weeks in a greenhouse subsequent to 3 or 6 weeks of storage at 5C. Nonstored control plantlets were transplanted into greenhouse after 2 weeks of culture (Expt. 2). ${ }^{\mathrm{z}}$ Means \pm SE are shown.

\begin{tabular}{|c|c|c|c|}
\hline Light & $\begin{array}{l}\text { Dry wt } \\
\text { (g) }\end{array}$ & $\begin{array}{c}\text { No. } \\
\text { leaves }\end{array}$ & $\begin{array}{c}\text { Stem length } \\
(\mathrm{mm})\end{array}$ \\
\hline \multicolumn{4}{|c|}{ Nonstored control A } \\
\hline & $18 \pm 0.01$ & $18 \pm 0.4$ & $236 \pm 38$ \\
\hline & \multicolumn{3}{|c|}{ After 3 weeks of storage } \\
\hline Blue & $16 \pm 1.8^{\mathrm{Ns}}$ & $17 \pm 1.8^{\mathrm{Ns}}$ & $242 \pm 9^{\mathrm{Ns}}$ \\
\hline Red & $18 \pm 0.4^{\mathrm{Ns}}$ & $18 \pm 0.8^{\text {ss }}$ & $259 \pm 6^{\mathrm{Ns}}$ \\
\hline White & $17 \pm 2.1^{\mathrm{Ns}}$ & $16 \pm 0.2^{\mathrm{ss}}$ & $223 \pm 33^{\text {Ns }}$ \\
\hline \multirow[t]{3}{*}{ ANOVA $^{y}$} & NS & NS & NS \\
\hline & \multicolumn{2}{|c|}{ Nonstored control B } & \\
\hline & $22 \pm 0.1$ & $19 \pm 0.3$ & $235 \pm 19$ \\
\hline & \multicolumn{2}{|c|}{ After 6 weeks of storage } & \\
\hline Blue & $23 \pm 0.6^{\mathrm{Ns}}$ & $22 \pm 0.2^{*}$ & $240 \pm 83^{\mathrm{Ns}}$ \\
\hline Red & $18 \pm 3.1^{\mathrm{Ns}}$ & $19 \pm 2.3^{\mathrm{Ns}}$ & $256 \pm 81^{\mathrm{Ns}}$ \\
\hline White & $18 \pm 0.2^{* *}$ & $20 \pm 0.5^{\mathrm{Ns}}$ & $231 \pm 56^{\mathrm{Ns}}$ \\
\hline ANOVA $^{y}$ & NS & NS & NS \\
\hline
\end{tabular}

${ }^{2}$ Data for 3 weeks and 6 weeks of storage were compared with nonstored control A and nonstored control B, respectively.

${ }^{y}$ Significance among the blue, red, and white light treatments; ANOVA = analysis of variance.

${ }^{\mathrm{Ns}, *, * *}$ Nonsignificantly or significantly different from those of nonstored control at $P \leq 0.05$ or 0.01 , respectively.

plant tissue cultures, p. 517-538. In: J. AitkenChristie, T. Kozai, and M.A.L. Smith (eds.). Automation and environmental control in plant tissue culture. Kluwer Academic Publishers, The Netherlands.

Kozai, T., K. Fujiwara, and I. Watanabe. 1986. Fundamental studies on environments in plant tissue culture vessels. (2) Effects of stoppers and vessels on gas exchange rates between inside and outside of vessels closed with stoppers. J. Agr. Meteorol. 42(2):119-127.

Kubota, C. and T. Kozai. 1994. Low-temperature storage for quality preservation and growth suppression of broccoli plantlets cultured in vitro. HortScience 29:1191-1194.

Kubota, C. and T. Kozai. 1995. Low-temperature storage of transplants at the light compensation point: Air temperature and light intensity for growth suppression and quality preservation. Scientia Hort. 61:193-204.

Kubota, C., G. Niu, and T. Kozai. 1995. Low temperature storage for production management of in vitro plants: Effects of air temperature and light intensity on preservation of plantlet dry weight and quality during storage. Acta Hort. 393:103-110.

Maijer, G. 1968. Rapid growth inhibition of gherkin hypocotyls in blue light. Acta Bot. Neerl. 17:914.

Moran, R. 1982. Formulae for determination of chlorophyllous pigments extracted with $\mathrm{N}, \mathrm{N}$ dimethylformamide. Plant Physiol. 69:13761381.

Mortensen, L.M. and E. Stromme. 1987. Effects of light quality on some greenhouse crops. Scientia Hort. 33:27-36.

Murashige, T. and F. Skoog. 1962. A revised medium for rapid growth and bioassays with tobacco tissue cultures. Physiol. Plant. 15:473497.

Reed, B.M. 1993. Improved survival of in vitrostored Rubus germplasm. J. Amer. Soc. Hort. Sci. 118:890-895.

Smith,H. 1982. Light quality, photoperception and plant strategy. Annu. Rev. Plant Physiol. 33:481-518. 